\title{
Learning to cite authority to develop arguments in academic discussions
}

\author{
Florence Sau-Fong Mah \\ Inti International University \\ Nilai, Malaysia \\ fiorencesf.mah@newinti.edu.my
}

\author{
Dr Su-Hie Ting \\ Universiti Malaysia Sarawak \\ Kota Samarahan, Malaysia \\ shting@cls.unimas.my
}

\begin{abstract}
The study examines university students' writing of the discussion text from the aspects of macro organisational structure, language features and citation practices. The study was conducted in a public university and a private university in Malaysia. The students were given four texts on a selected topic and asked to extract relevant points for discussing a given issue. Prior to this, they had been taught how to cite authoritative sources. The analysis of $\mathbf{7 2}$ discussion texts indicated that while students provided supporting evidence for arguments, the ability to formulate the issue and the main ideas was weaker. The modal verbs frequently used as hedging devices were can, could and may. Connectors were frequently used to develop arguments as well as to signal similar and contrasting viewpoints but there was a lack of variety in connectors used. To report authoritative sources, the students were balanced in their focus on author and information in their citations. However, the reporting verbs they relied on indicated an attitude of reporting facts. The findings suggest that an important skill to teach in academic writing is the use of reporting verbs to show degree of commitment to the cited claims.
\end{abstract}

\section{Keywords-academic writing; discussion; citation}

\section{INTRODUCTION}

In the study of academic discourse, student learning of academic writing skills has been a focal area of research. Studies have shown that university students have problems acquiring the skills of writing expected by their discipline lecturers (e.g., Zhu, 2004). From a text-based writing perspective, sometimes the written assignments do not fulfil the genre conventions (Ting \& Law, 2008; Ting \& Tee, 2008). Nevertheless, the better writers have been found to produce better organised argumentative essays compared to the weaker students (Jenkins \& Pico, 2006; Ting, Raslie, \& Jee, 2011).

In spite of this, good academic writing skills requires more than proficiency in the language as students need to engage with specialised meanings of disciplines and notions of intertexuality. In academic writing, personal knowledge and impressionistic interpretations are not valued as much as reorganisation and critique of knowledge (Grabe \& Kaplan, 1996; Horowitz, 1986). The ability to draw from and depend on other texts requires the awareness of intertexuality (Johns, 1997) which is reflected in citations and references, and how these are incorporated into the text to develop ideas. Thus far, research that deals with intertexuality in academic writing has tended to focus on the construction of the author identity (e.g., Hyland, 2002; Ramanathan \& Atkinson, 1999) and citation practices in academic publications (Hyland, 2003) or the lack, thereof, plagiarism (Chandrasoma, Thompson, \& Pennycook, 2004; Phan, 2006).

Studies that focus on students' mastery of academic writing skills have tended to analyse texts without citation (e.g., Hinkel, 2004) whereas studies on citation practices are not set in the context of skills displayed in writing of various texttypes. Considering that university students are expected to demonstrate mastery of their discipline and, in the process, draw on various authoritative sources in their academic writing, it is important to study students' citation practices along with their writing skills. For example, "we may want to understand how students learn to write arguments informed by the best knowledge available" (Bazerman, 2004, p. 83). Part of the academic writing skills at university level is the ability to position the text and draw on relevant textual resources, and this is reflected in the citations incorporated into the academic text.

The study examines how students incorporate authoritative sources in their discussion of an issue. The specific aspects examined are the macro structure of the discussion text, important language features of discussion texts and the citation practices.

\section{METHOD OF STUDY}

\section{A. Corpus of Discussion Texts}

The discussion texts were written by students in two Malaysian universities. In both universities, the students were enrolled in Academic Reading and Writing courses in which students learnt American Psychological Association (APA) style for citation and referencing as well as the features of explanations, classification essays and discussions. For their coursework assignments, students were required to incorporate citation of authoritative sources in their essays.

To collect the data for the study, the discussion essays written by the students in class were taken for analysis. At the beginning of the two-hour class, students were given four texts on a selected topic and asked to extract relevant points for discussing the given issue, which is "Should genetically modified food be banned?" The same procedure was followed 